\title{
The many pathways an oocyte can take to achieve a term pregnancy
}

\section{David F. Albertini ${ }^{1}$}

Published online: 19 June 2019

(C) Springer Science+Business Media, LLC, part of Springer Nature 2019

So much for the good old-fashioned way to make a baby. Our reproductive medicine and biology forebears from days gone by set the stage for manipulating hominid reproduction in ways that could have been hardly imaginable. We speak often in these pages of advance after advance as the foreskin of assisted reproductive technology keeps pulling back the margin of what is feasible to what is marketable. This month, we take a closer look at what the ability to cryopreserve gametes and tissues has contributed to the landscape of human ARTs.

At the top of the agenda is the topic of "egg" freezing or oocyte cryopreservation (OC). We live in a world where the shedding of the "experimental" moniker attached to OC just over 5 years ago unleashed a move to convince many elements of society to bypass the innate age-related limits of human reproduction in women (i.e., ovarian aging) by extending human fecundity by another decade or so. Buttressed by the notable success of vitrification, relative to the somewhat diminished survival rates reported for thawed slow-frozen oocytes, we have found ourselves in the midst of vitrifying eggs, sperm, embryos, and gonadal tissues for purposes well beyond that of extending the reproductive lifespan of Homo sapiens. Two driving forces have led the way.

First, back in the 1990s, practitioners in Italy were posed with the dilemma of how to address their patients' needs after a ban on embryo cryopreservation was imposed. As a result, the much needed basic science and clinical validation for OC spread through many countries as technology transited from the days of slow freezing to that of vitrification, hence the linguistical transformation from the world of thawing to warming even though standardization of technology for the latter remains a subject of refinement and manipulation.

David F. Albertini

eicjarg@gmail.com

1 Center for Human Reproduction, New York, NY, USA
Next, we entered the era of fertility preservation. While the initial motivation for this effort had its roots in preserving fertility for patients undergoing gonadotoxic treatments, the technologies and protocols evolving from those efforts now find application and utility for a number of conditions that warrant stashing germ plasm, either pre- or post-fertilization, for use at a later time. Short of making gametes from scratch, say for example from stem cells (see next month's issue), the harnessing of $\mathrm{OC}$ and its male gamete, embryonic, and tissue corollaries via vitrification has become a mainstay of human ARTs as practiced today.

With this ever-widening increase in bandwidth for $\mathrm{OC}$ and related storage approaches comes negative consequences such as the tank failures reported last year. To this end, our readership will benefit from having a close look at the paper by Moutos, Lahham, and Phelps as a guide for what to anticipate should incidents like this come closer to home (Cryostorage failures: a medicolegal review, https://doi.org/10.1007/ s10815-019-01478).

Among the many unresolved questions pertaining to $\mathrm{OC}$ as its utility for family planning plays out in the future are those having to do with longer term outcomes for patients and offspring as well as what the return rate is for patients who in the past have opted in for OC. The paper by Gu and colleagues from the U.K. takes a retrospective look at this and provides an important baseline for the $\mathrm{OC}$ rage and the implicit decision-making process that goes along with choosing alternative pathways to family planning in the future (For whom the egg thaws: insights from an analysis of 10 years of frozen egg thaw data from two UK clinics, 2008-2017 https://doi. org/10.1007/s10815-019-01429).

One of the important roles that the medical literature fulfills is to offer professionals a chance to view their practices in respect to thematic variations existing between countries. JARG takes this point to heart, and given the wide range of regulatory (or not), legal, and ethical practices for human ARTs, just how different countries are exploring and exploiting OC remain a matter of discussion. Specifically to the point of elective OC, Inhorn and her colleagues have begun to weigh in on this matter comparing in a preliminary way 
of attitudes and practices for Israel and Italy (Patient-centered elective egg freezing: a binational qualitative study of best practices for women's quality of care https://doi.org/10. 1007/s10815-019-01481).

Moving on to the matter of embryo cryopreservation and the apparent extension of embryo culture times affording the insertion of tests promising better selection outcomes, the debate over fresh versus frozen continues in our field with the option to freeze (i.e., vitrify) key to invasive technologies like PGT-A.

Taking a step back, the review and meta-analysis by Simopoulou and colleagues in Athens examines trends that once again illustrate varying attitudes and practices with emphasis on the principle of extended culture and the value of monitoring longer term behaviors of human embryos ostensibly to gain insight into what embryos are most likely to result in a term gestation (Should the flexibility enabled by performing a day-4 embryo transfer remain as a valid option in the IVF laboratory? A systematic review and network metaanalysis, https://doi.org/10.1007/s10815-019-01475).
Questions like this are far from resolved and fail to withstand the test of time in the changing landscape of human ARTs as it has segued from the world of infertility treatment to that of family planning. In the end, whether baby making follows the traditional course or that involving ARTs, time will tell what the impact of our changing world will have on the health of children conceived in different ways. And with this in mind, studies are beginning to appear taking a more careful look at parameters of offspring health that well exceed the tools used to date for addressing such important questions (PCSK9 and Lp(a) levels of children born after assisted reproduction technologies, https://doi.org/10.1007/s10815-019-01474).

We hope you enjoy the range of articles this month and draw your attention to next month's issue that will be emphasizing exciting new results on male gametes and efforts to generate healthy sperm with novel selection strategies.

Publisher's note Springer Nature remains neutral with regard to jurisdictional claims in published maps and institutional affiliations. 